\title{
The landscape theory by Bernard Lassus: an Italian example ${ }^{(1)}$
}

\author{
PAOLA CAPONE(2)
}

Bernard Lassus is an artist who has devoted his life to discovering places, to revealing their landscapes, in constant, critical and tight dialogue with the architecture, giving it the ancient dignity that bears its name: the art of supervising. Aristotle docet.

The theory of landscape by Bernard Lassus comes from afar, from rigorous research on visibility: light, color and appearance, leading to the garden as a landscape perspective, where the deeply rooted infrastructure opens up to the local, in the rapid evolution of globalization.

A landscape is defined by its visible horizon, it is recognizable by its look, reflecting the living synthesis of people and places, based on an immeasurable imagination. The practice is theory at the same time. One leads to the other and vice versa, in an indissoluble bind. It gets into places in order to understand the presence of objects and their relationships that give identity to a landscape and grab its unique image, its identity, its depth. Characteristics to be retrieved for their future.

The relationship between objects and landscape is complex, ambiguous and mutually destructive. The widespread use of the term "landscape" and the continuing search for a definition is proof of how difficult it is to grasp the articulated connections between objects.

The focus on these relationships is central to the practice of landscaping, based on the first glance that only covers part of the concrete space of the visual scale, where several individual parts come into a visible unity, often partially open to the look. Landscape is basically a case of our gaze on our surroundings. It is not the most visible and the invisible, a continuous interplay between the seen and hidden, real and imaginary, a game of imagination that animates a particular dèmarche, a working tool designed to reveal the landscape, not to define it. There is no practice without theory and vice versa: a careful arrangement of the plots of happening places, between reality and appearance: a march evident in all its projects.

Bernard Lassus has developed a practice that includes landscapes, in the proper sense of the pre-vision with his tools. Let us trace his theoretical path. The visible leads to the relationship between light and color, the visual and tactile impressions with different suggestions. Light, color, visibility and imagination are the terms of an original and classic perception of the landscape. Supporting the heterogeneity of a single world, where things appear and may be other than they are. A human world, which can be different depending on the choices made by the forecast. He obeys a project: a critical landscape. The portrait of the human work and its possibility. Since the early 1950s, Lassus' research starts from the relationship between color and appearance. The theme will never leave, as evidenced by his last book: Couleur, lumière... paysage. Instants d'une pédagogie, Èditione du patrimoine, Paris 2004, summa of his work. History of the materials, their movement between integration and diversity, history of old and new patterns that lead to locate a game of appearances between visibility and physical reality: a game that requires overcoming habits and clichés, especially when considering the placement of the thing and its context, its environment. The essence of the thing is its location. If we extrapolate we do not understand it well. The color is landscape: it claims the totality of its scope. In this context, the architecture blends with the landscape, or the contrary.

Landscape and color are more intimate than we can imagine. Lassus elaborates a theory of vision increasingly perfected by research and experiments on the difference between visibility and physical reality: a discrepancy at the bottom of each reported landscape, where the relationship between things and the environment is crucial. Environment is a unified visual space filled with objects that characterize it.

The objects form a plot. The landscape is not a combination of things, it's simply a container. Objects make up a whole and enhance one another to establish the relationships between them without overlapping the other. If you move, the story changes. The framework is supported by two beautiful metaphors: the bouquet of flowers and perfume.

The single element should not be separated from the universe in which it appears. Another "metaphor" of glasses and bottles, clearly shows that a landscape is a unique image with multiple elements, an image with its specificity, with its peculiar character. An image determined by the landscape, its relationship formed by the place that each object occupies in relation to the other elements. Visual frames of the environment is the study of the conditions spatially distributed around an object and in dynamic interaction with it. Research by Lassus has moved from these restricted areas, clubs, in order to understand the landscape. From these the environment is as a study object of ecology which falls. The research is based on gradual steps leading to the basics from the object and its positioning. A context to keep in mind, to see the relationships. Here we also find the conditions of the heterogeneous, key proposition of the dèmarche of Lassus. The viewpoint, tactile platform that opens the horizon and leads us to the highway in a modern conception of the perception of identity, from here, the dissociation between object and landscape, which allows one to identify the individual elements of a whole. Two major issues open: visual information and tactile and visual dimensions. High moments of reflection that lead to distinguish the places from its landscape, with the passing

\footnotetext{
(1) Recebido em 10 de maio de 2013 e aceito para publicação em 30 junho de 2013.

(2) Professora, Universitá degli Studi di Salerno
} 
of the concept of non-place with the categories of visual and tactile scales, re-evaluating the game light / color, natural / artificial movement of the observer and / or the movement of the object. Another great indication useful for landscape architecture. To be seized.

The appearance finds its full development in the research on breeze-light and the tulip on the difference between reality and appearance, with a "revolutionary" statement: to change a landscape, physical transformation is not needed; only a minimal intervention is sufficient, and often more effective. This opens up to a new interpretation of the landscape. It is the "job" of the gardener. The appearance of the concrete conditions and even more consciousness. Lassus then processes the techniques apparently involving two scales: that of the Dweller and the other of the landscape. Two different perceptions and two different landscapes. Information, redundancy and miniaturization are some of the real creators of the entities of the landscape with the objective conditioning between tactile and visual, between the inhabitant and the landscape.

The concepts are perfected with games and visual experiences. The red dots game, moving, processing of appearance, are stages on a path between the finiteness of our world that flows in the imagination, in the demisurabile, the soul of its theory and its practice: the proposal for the new landscapes. The future are gardens with depth: the horizon has now been verticality overthrown. Lassus' research behind the work of unknown masters: the landscape inhabitants was dedicated to the study of the Paris suburbs that lasted 15 years : a survey which understood the mechanisms of aesthetic plastic popular landscaping. The banlieues of Paris offered true imaginary gardens in narrow spaces between houses and gates of houses or painted on the walls of the buildings.

The people are the masters of Bernard Lassus: the development of his personal design practice is credited to them. They are simple residents who have made a change to their living environment, their home. Dissatisfied with the original condition of the space assigned to them by the manufacturer, they have created garden-landscape miniatures, at different scales, which have received their imagery, often inspired by a dream world, a world of fairy tale, of the forest and the fragments of a natural death. A dream space where every creation is of no practical benefit.

The eyes of the observer, entering these landscaped houses, captures one tactile space, measured, visibility unlimited, to read and learn. Only those who participate in the dream may be included in the vertical imaginary that gives life to the place: the garden.

Lassus' in-depth look has never abandoned the imaginary gardens since 1961, the year in which a search that would open a new demo-etno-anthropological perspective of landscaping would begin, merged into the demisurabile. An original dèmarche was in the project Le puits, the theoretical and practical example derived from Snow White sitting on a well, looking at the disappearing forest, the dream that invites us all to imagine landscapes, not to lay green carpets.

Claude Lévi-Strauss considered Jardins Imaginaires, a new field in demo-etno-anthropological studies.

Lassus developed a landscape practice, where the creative subject and place are intimately connected, a dèmarche transferable in reality, perfected over time with experience and continuous reflection on the traces of a method. A process that does not process objects, but relations, and relationships of landscape: landscape processes. This opens an aesthetic which is deeply rooted in the places and is based on the imaginary. Aesthetics as a practice of landscaping.

The activity of the 'Dweller landscapers' has revealed the existence of a native substratum, a ground on which society, often through the architect, builds a support to which everyone gives his contribution: the contribution of his experience. This distinction explains the three levels of intervention landscaping and allows you to make landscaping a practice. There is a contribution amending an objective to support an original reality. The change can be done in two different ways: by integrating or diversifying, that is to say opening heterogeneous: welcoming, understanding and acceptance of a balanced relationship of the different characters or fractions. The practice of landscaping can thus attain the appearance of the artificial as another expression of the "natural", this limit - in the Jardin du Jeu des Saisons, the meanings are open to multicultural interpretation made at the headquarters of the company Colas SA in Boulogne Billancourt.

Imagining and composing landscapes is a subtle, sharp and incisive game, based on the contribution and is open to the possibilities offered by a place, from its substrate. This dynamic identifies the prospect of recovery from deterioration or possible intervention in a critical means, the examination of all the possibilities with an eye to the past, toward the future. The future is the project.

The city itself is in reality becoming like every place and landscape. The dialogue is between the future and the past and vice versa. Lassus looks to the future to probe the depths and give a function, or make sense.

This dynamic lies within the boundaries of a finished landscape, devoid of forest, whose absence has become a metaphor for a world known, predictable, where the landscaping needs imagination in order to provoke emotion. The gardens at the front, the original project - unreleased like many others, perhaps too advanced for our age - suggests feelings of digging deep into the abyss of the history of a new city, supported by a natural space that opens to the immeasurable imagination: the memory of the garden city, an ancient monument of the city center.

The existing is revealed by creative analysis, the project outline, the starting point of any practice of landscaping. A landscape architect should be well informed by a multidisciplinary and demo-etno-anthopological survey, aided by various specialists that offer data of a certain territory. The collection of such information thus shows the existing with a view to new contributions, maintaining the potential of the single sites. In this way you can know a site to approach it in its particularity - in its history and in its full potential.

The floating attention is another central concept that involves the different variations and depths inherent in places subject to change and then flexed. You need to be the observer, a sponge soaking up the earth several times from the ground to the sky to find the best points of view, micro-landscapes 
with the prospects that bind them and you can try to visualize the tactile stairs. Archival research remains essential in discovering the depth: legends, literature and history. Thus, once again to light the hidden, conceal from the oblivion of everyday life. The places are full of layers that need to be re-evaluated through the interweaving of their fractions, as evidenced by the project for The Tuileries Garden.

The landscape does not superimpose, but reveals the extent of landscape with its different scales of identity, that have emerged from inventive analysis that shows the layering of the different temporalities of the various landscape which has evolved over the years. These conditions make the garden a place where you discover the tactile vision: an immeasurable art exhibition. You enter a place of transition between visual and tactile: the place of contradictions and dissociation. All of them are located in the faults of a mille-feuille landscape.

The verticality of the new landscapes can be read in the projects of Rochefort-sur-mer with Il giardino dei ritorni e delle Città - colori - paesaggi della Lorena: garden towns. The landscape values of the area are safe and are included in the process of transformation of places and landscapes, flexibility thanks to the practice of inflections in the landscape.

Lassus proposes an art of transformation: a process as a set of interactive movements of a place, without stopping it or fixing it, but catching it on the way. Everything changes, nothing remains. Even the landscaping, art of transformation, motion, journey, it is a practice linked to fixed theoretical principles. It is flexed - let's say that once again. This is perhaps the clearest lesson of Lassus. The ideas walk with a man's legs. His action changes over time. It is relentless with strategies and solutions to improve the global and limited place of life.

The lines of communication are always faster and the infrastructures are more impressive and necessary. The conversion shall be governed and imagination has to propose solutions. Landscape gardens take this direction: the direction of the path that requires rapid intermediate places to stop and explore the locality. Only the place in its tactile reality can allow you to see new and old, modern and ancient landscapes.

The look captures the depth of human life, its culture that is and remains ethical, it is local. The highways are transformed into moving viewpoints, passing through the gardens where the traveler can stop and play his role as a informed landscaper, who is informed by the quality of existing places in our world and experiences the thrill of the balance between tactile and visual: re-evaluate the position of the body with its senses.
Democratic landscape politics can only be addressed to the local knowledge and participation of the people, in the choice of paths that can enhance their own landscapes. The discovery of places is the long shadow of multiculturalism, of belonging and acceptance. These are moments of a journey towards the heterogeneous with its contradictions and its varieties, to make the lives of all the people nice and cozy, near and far: a pleasant journey for the eyes and spirit through the gardens of the discovery. A lesson not to be forgotten: a new garden for our world, an open path, as the entity of a landscape. The path of modern Archegeta that leads to the discovery of the depth of the sites, the architect as designer, creator of practice for the landscape.

These are the theoretical points of the project that Bernard Lassus presented to Baia dei Pini, a residential park located between Agnone and Acciaroli in the area of Mezzatorre in the town of San Mauro Cilento (SA), published by Paola Capone, collaborator of the project, in the book Il restauro impossibile. Un progetto di Bernard Lassus per il Cilento, Area Blu Edizioni, Cava de' Tirreni 2012. Its cluster of white houses, seen from the sea, is presented as a "great stain" that interrupts, along with almost all the other buildings on the coast, the typical colors of the flora and the local rocks.

For Lassus it is the Nature, generally seen as "background," which is usually taken as a "model" in order to return a new vision of the complex functions of organisms and processes that govern the landscape: this is the basis for giving body to "taking form" of sustainability, to achieve a "concrete utopia".

Baia dei Pini is an example that may suggest a new way to deal with the inquiry of architecture and landscape using not only traditional knowledge, historical or scientific, and of their clear and distinct perception, but also a complex, refined by a singular vision and hearing. The challenge of this reflection is to put the question on the need for more extensive training of those who work in this field. Essential is the knowledge that not all skills are extinguished by related traditional knowledge, but that the level of interpretation is also influenced by the Weltanschauung of the interpreter.

In conclusion, if done properly, with a "weak" scientific statute, and not with eyes turned to the rules canonized until now by institutional traders, with close constructive collaboration, as it was in this case, you will have the inventive analysis, that with Panofsky we might call iconological analysis, to form the basis of the project, beyond the sensitivity of everyone, will give rise to new landscapes. 